\title{
Normalization of Thyroid Stimulating Hormone Levels in Acromegalic Patients after Selective Adenomectomy
}

\author{
Hiroyasu TSUChiy ${ }^{1}$, Toshio ONISHI ${ }^{1}$, Shintaro MORI ${ }^{3}$, Shoushi LEE $^{1}$, \\ Hiroshi KOHNO ${ }^{1}$, Shunj IMANAKA ${ }^{1}$, Youichi SAITOH ${ }^{2}$, \\ Heitaro MOGAMI ${ }^{2}$, Tohru UOZUMI ${ }^{4}$ and YUichi KUMAHARA ${ }^{1}$
}

${ }^{1}$ Departments of Medicine and Geriatrics, and ${ }^{2}$ Neurosurgery, Osaka University Medical School, Osaka 553;

${ }^{3}$ Department of Neurosurgery, Center for Adult Diseases, Osaka 537 ; and ${ }^{4}$ Department of Neurosurgery, Hiroshima University

Medical School, Hiroshima 734

\begin{abstract}
Changes in TSH secretion in six acromegalic patients were studied before and after transsphenoidal adenomectomy (Hardy's method) and compared to normal subjects and six patients with prolactinoma. Basal serum GH levels ranging from 5 to over $250 \mathrm{ng} / \mathrm{ml}$ before adenomectomy decreased to below $5 \mathrm{ng} / \mathrm{ml}$ after the operation, and the abnormal responses of GH to TRH observed initially in three of the six patients almost disappeared in the postadenomectomy period. The response of serum TSH to TRH in acromegalic patients improved in each of the six patients after the operation. The TRHstimulated TSH secretion in patients with prolactinoma of a size and grade similar to those in acromegalic patients was not so extremely low as that in the acromegalic subjects. As indicators of thyroid function, serum triiodothyronine $\left(\mathrm{T}_{3}\right)$, thyroxine $\left(\mathrm{T}_{4}\right), \mathrm{T}_{3}$-uptake levels and free $\mathrm{T}_{4}$ indices did not change significantly after adenomectomy as compared with those before the operation in five of the six patients tested. Serum $\mathrm{T}_{3}, \mathrm{~T}_{4}$ and $\mathrm{T}_{3}$-uptake levels and free $T_{4}$ indices before adenomectomy were normal or subnormal in each patient except for a high serum $T_{4}$ level and free $T_{4}$ index before the operation in only one patient. Thus, it is difficult to conclude that the function of thyrotrophs was decreased by pressure upon the intact pituitary gland by the tumor, or that the thyroid gland also became hypertrophic secondary to the elevated $\mathrm{GH}$, resulting in a large quantity of thyroid hormone being secreted, which caused a suppression of TSH secretion by negative feedback. The data suggest instead that the secretion of GH and TSH from the intact pituitary gland is inhibited due to the autonomous production of excessive GH from the tumor, which may also suppress growth hormone releasing factor secretion and accelerate SRIF secretion from the hypothalamus.
\end{abstract}

The response of serum TSH to TRH is diminished in acromegalic patients (Sakoda et al., 1970; Karlberg et al., 1971; Gual et 
al., 1972; Hall et al., 1972 ; Irie et al., 1972; Kumahara et al., 1975). Pressure on the normal pituitary gland by a pituitary tumor or the effect on TSH secretion of excessive secretion of $\mathrm{GH}$ is considered to be the cause of the decreased TSH secretion in acromegalic patients. In this investigation we report the changes in TSH secretion in acromegalic patients before and after adenomectomy and compared the results with normal subjects and patients with prolactinoma.

\section{Materials and Methods}

\section{Subjects}

Six patients with acromegaly (patient number 1-6) were studied (Table 1). The tumor in each patient was determined to be an intrasellar microadenoma. None except patient No. 5 had received therapy prior to surgery. Six normal subjects matched in age and sex served as controls, and six women (aged 24-50 yr) with hyperprolactinemia and pituitary microadenomas whose prolactin level ranged from 118 to $325 \mathrm{ng} / \mathrm{ml}$, were examined for the purpose of comparison with the acromegalic patients.

\section{Laboratory Examinations}

Insulin tolerance tests (ITT: $0.1 \mathrm{U} / \mathrm{kg} \mathrm{BW}$, MC Novo Actrapid, iv) were conducted on each of the acromegalic patients before and approximately two weeks after surgery. TRH tests $(500 \mu \mathrm{g}, \mathrm{iv})$ also were performed before, approximately two weeks after, and three months after their operations. We also performed TRH tests to measure serum TSH in six normal subjects and six patients with prolactinoma. Serum GH, $\mathrm{TSH}, \mathrm{T}_{3}$ and $\mathrm{T}_{4}$ were measured by radioimmunoassay using commercial kits (GH : Dainabot RI Lab., Tokyo, TSH: Daiichi Radioisotope Lab., Tokyo, $T_{3}, T_{4}$ : Eiken Immunochemical Lab., Tokyo), and $T_{3}$-uptake was measured by a $T_{3} U$ MAA kit (Amersham International).

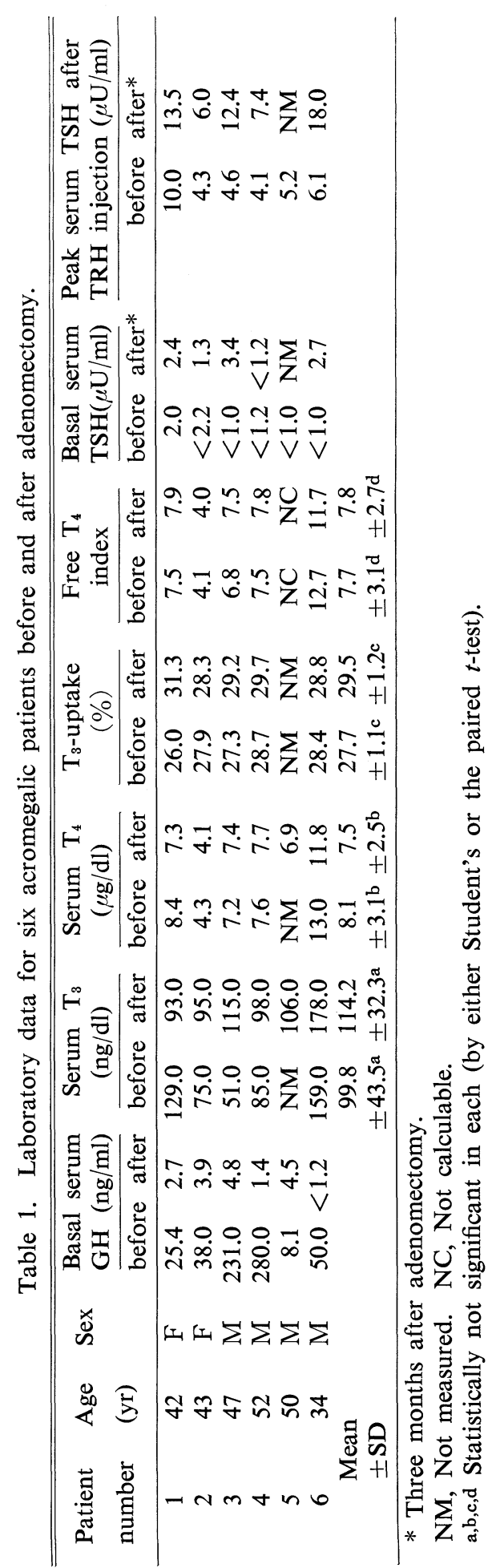




\section{Results}

The high basal level of serum GH in each acromegalic patient decreased to a level less than $5 \mathrm{ng} / \mathrm{ml}$ after adenomectomy. The levels of GH secretion after insulin administration to the patients before and after adenomectomy are shown in Fig. 1. The response of $\mathrm{GH}$ to insulin hypoglycemia was not observed in any of the subjects before or after surgery. Fig. 2 shows the GH secretion after TRH administration in each of the six acromegalic patients before and after adenomectomy. A rise in the GH level after TRH administration was observed in three (patients 3,5 and 6) of the six patients. The almost complete disapperance of a GH response to TRH in these three patients indicated that their pituitary adenomas were almost completely removed.

Fig. 3 shows the mean TSH levels after TRH administration (mean \pm SD) of the six acromegalic patients before adenomectomy, six patients with prolactinoma before operative therapy and six normal controls. The

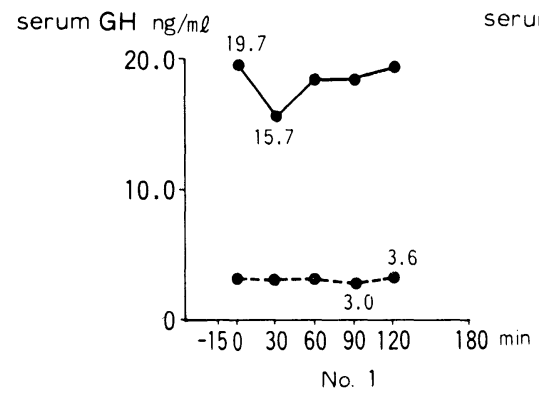

serum $\mathrm{GH}$
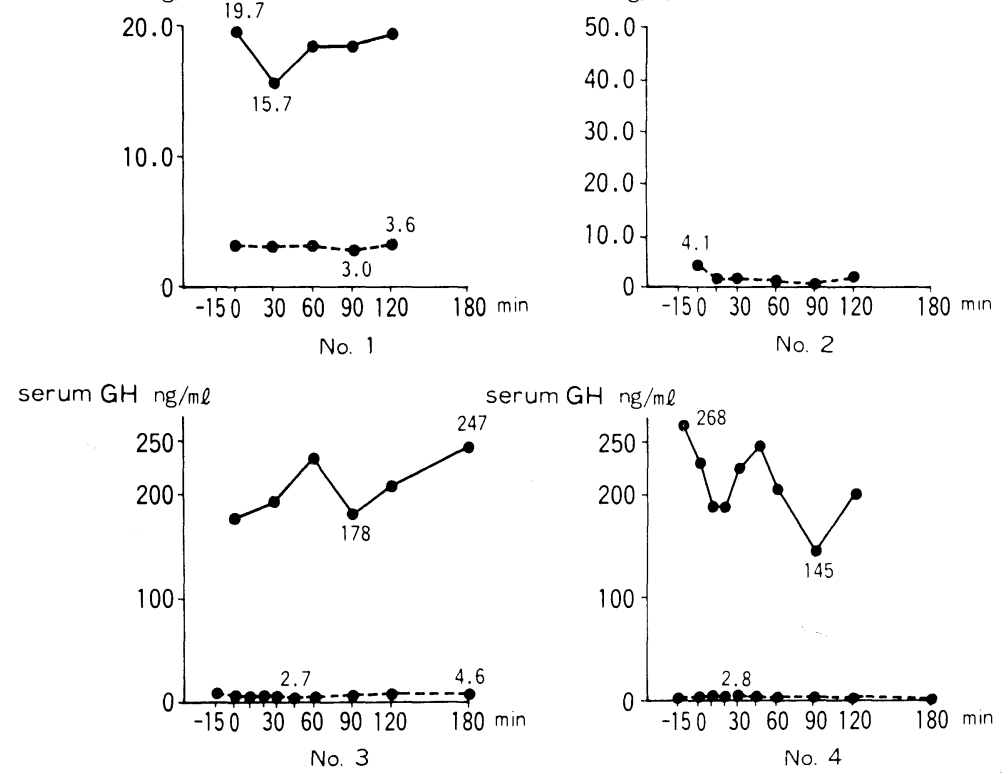

serum $\mathrm{GH} n \mathrm{ng} / \mathrm{m} \ell$

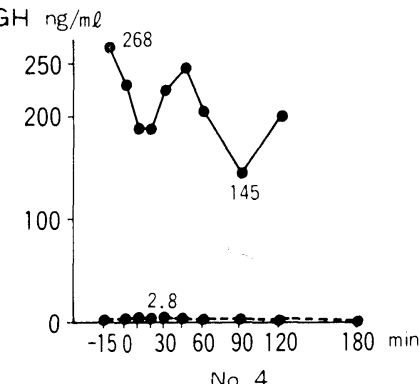

serum $\mathrm{GH} n \mathrm{ng} / \mathrm{m} \ell$
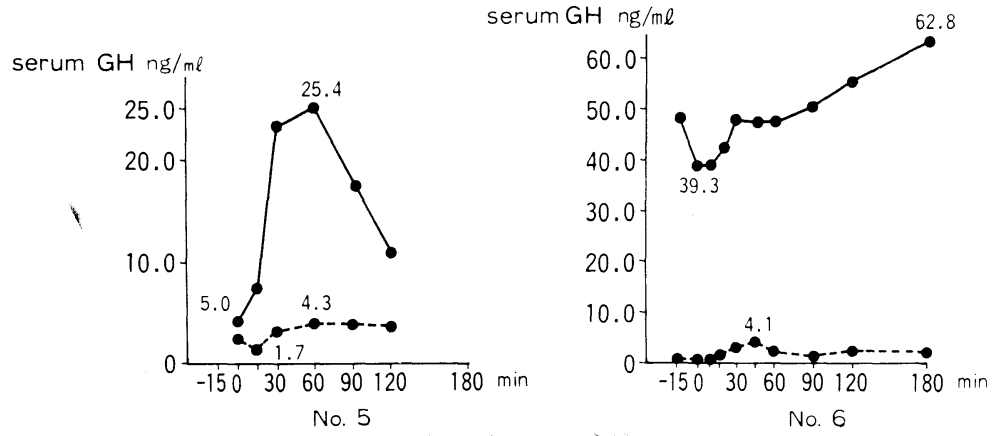

Fig. 1. GH secretion before and after adenomectomy during insulininduced hypoglycemia in six acromegalic patients. The patient number is indicated below each panel. Values before surgery were not obtained in patient No. 2. - Before surgery ; ---., two weeks after surgery. 
levels of TRH-stimulated TSH were significantly lower in the acromegalic patients than in those of normal subjects $(p<0.01)$ and the patients with prolactinoma $(\mathrm{p}<0.05)$. The levels of TRH-stimulated TSH in the six acromegalic patients before, about two weeks after, and three months after adenomectomy are shown in Fig. 4. Each patient showed a stronger response to TRH after, rather than before, adenomectomy. Only patient No. 2 showed a weaker response two weeks after the operation.

In three of five patients studied, the serum $\mathrm{T}_{3}$ level before adenomectomy was lower than the lowest limit for those of normal subjects. Serum $\mathrm{T}_{3}$ concentrations increased after the operation in all patients studied except patient No. 1, whose serum $\mathrm{T}_{3}$ level was within the normal range initially (Fig. 5). The serum $\mathrm{T}_{4}$ level and free $T_{4}$ index did not change significantly after adenomectomy in each of the five patients studied (Table 1). $\mathrm{T}_{3}$-uptake levels were all within the normal range both before and after surgical treatment, although each increased slightly (Fig. 5).

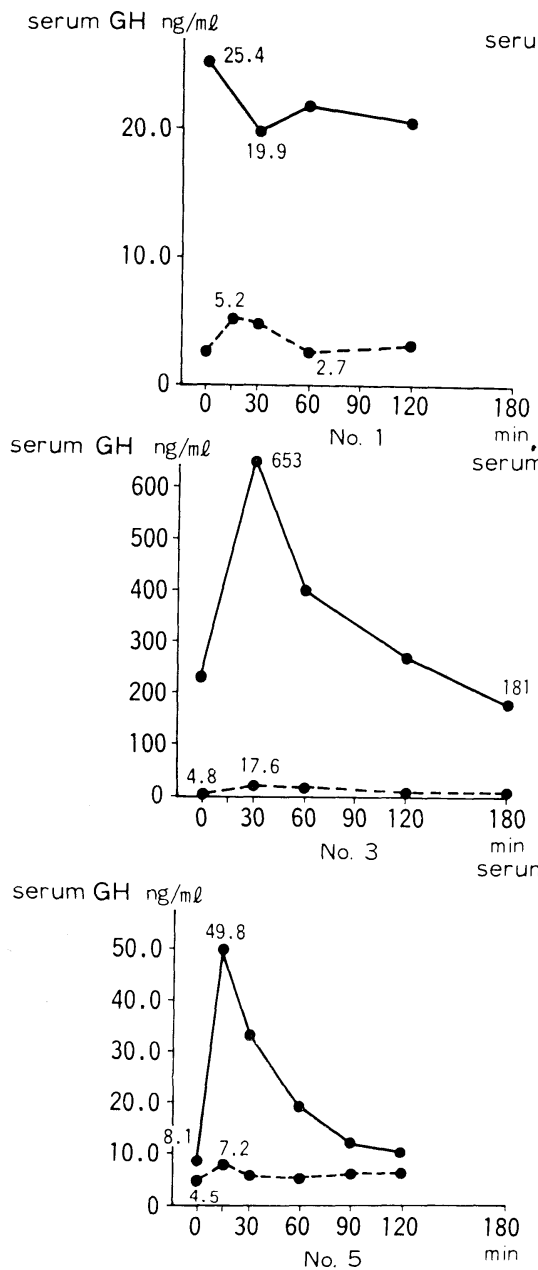

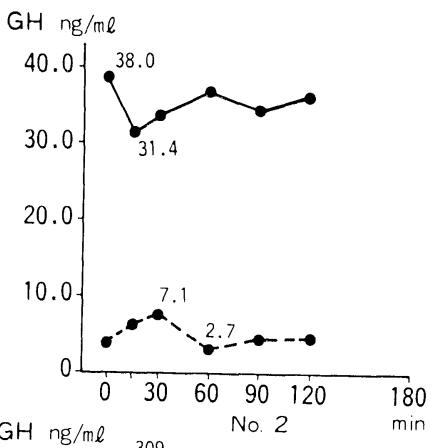
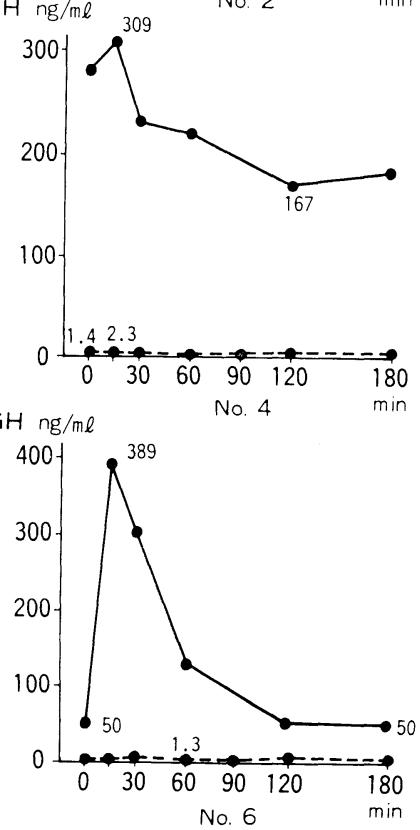

Fig. 2. GH secretion before and after adenomectomy after TRH injection in six acromegalic patients. The patient number is indicated below each panel. - - Before surgery; - - , two weeks after surgery. 
Fig. 4. TSH secretion before and after adenomectomy after TRH injection in six acromegalic patients. The patient number is indicated below each panel. Values for three months after surgery were not obtained for patient No. 5. Before surgery ; ---O, two weeks after surgery; $\bigcirc-O$, three months after surgery.

\section{serum TSH $\mu \mathrm{U} / \mathrm{m} \ell$}

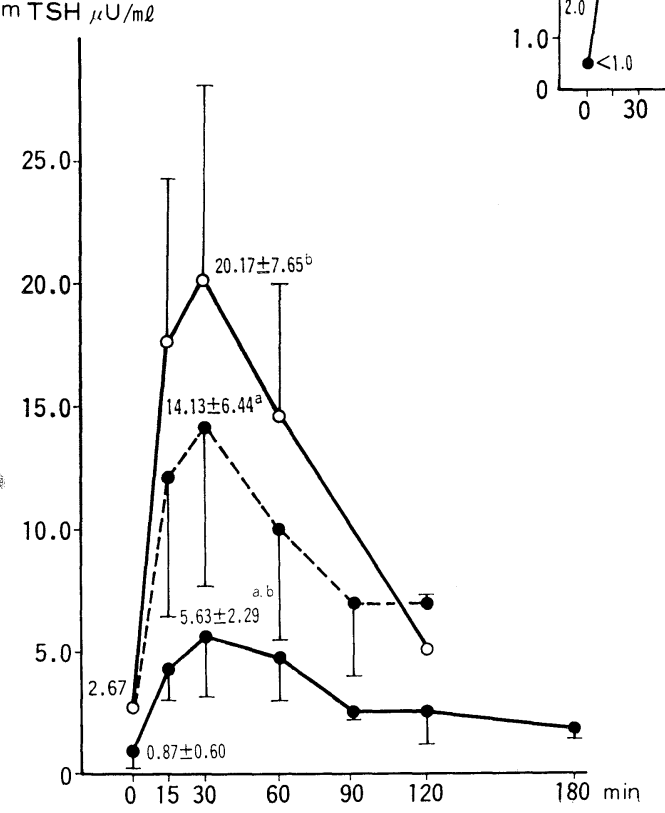

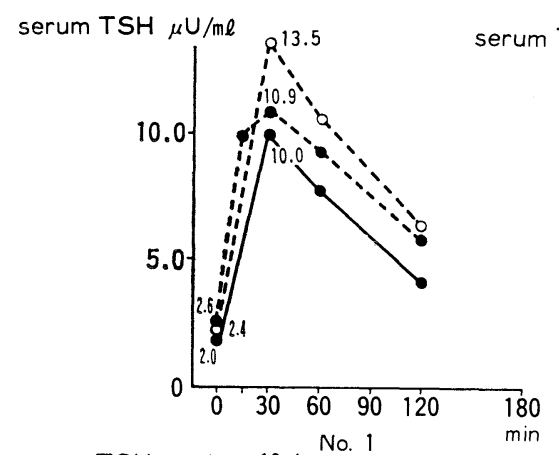
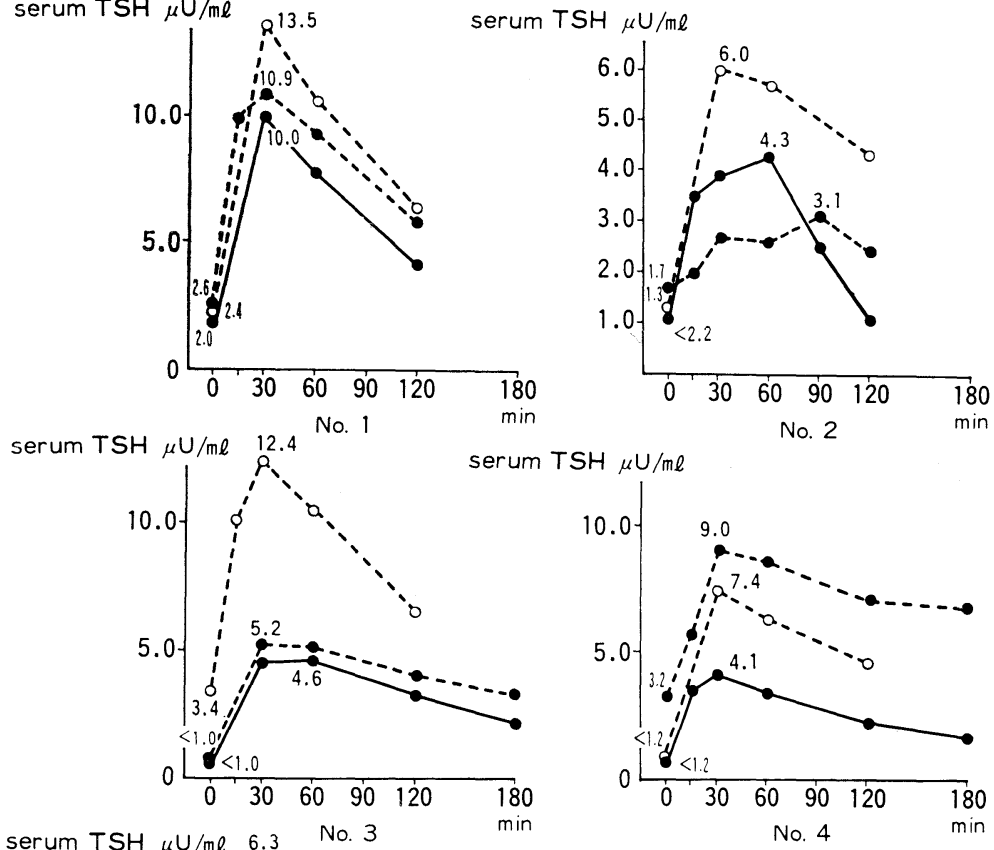

serum TSH $\mu \mathrm{U} / \mathrm{ml} 6.3$ serum TSH $\mu \mathrm{U} / \mathrm{ml}$
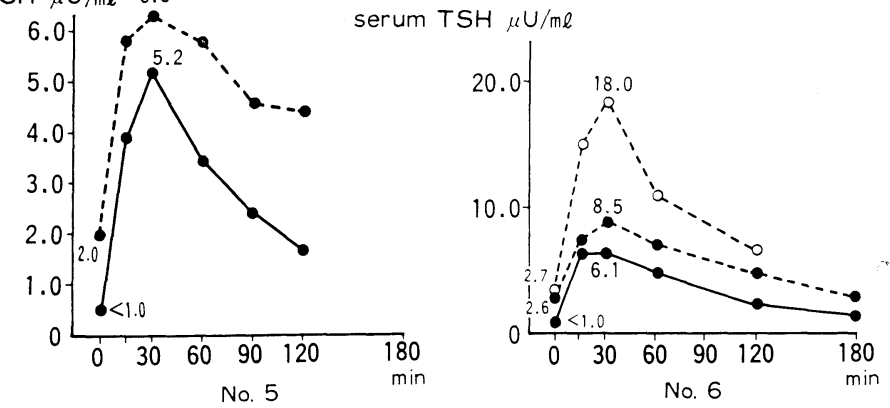

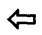

Fig. 3. TSH secretion after TRH injection in acromegalic patients, patients with prolactinoma and normal subjects. Each point is represented as mean \pm SD. - , Acromegalic patients before surgery $(n=6) ; 0-\cdots$, patients with prolactinoma before surgery $(n=6) ; \bigcirc-O$, normal subjects $(n=6) .{ }^{a} \mathrm{p}<$ $0.05 ; \mathrm{b} p<0.01$. 


\section{Discussion}

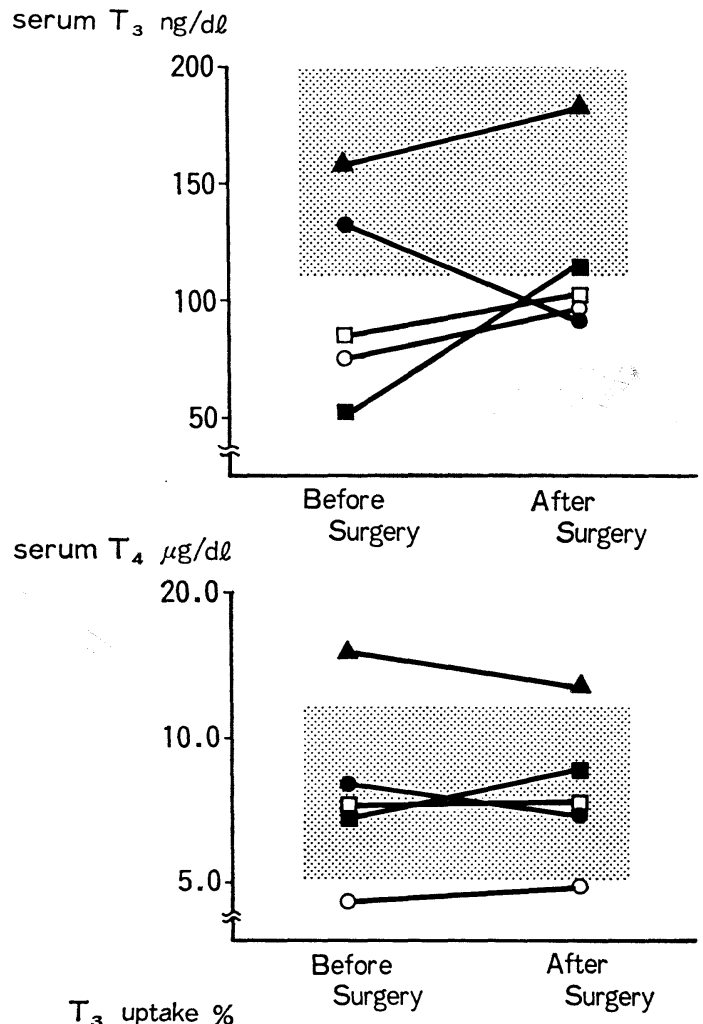

Some acromegalic patients with a normal serum GH level continue to show an abnormal $\mathrm{GH}$ response to TRH even after surgical therapy (Samaan et al., 1974 ; Giovanelli et al., 1976). Because the serum $\mathrm{GH}$ response to TRH is believed to be mediated by a direct pituitary action of TRH which probably is exerted on abnormal receptors of the adenomatous somatotrophs (Faglia et al., 1973; Giustina et al., 1974; Hoyte and Martin, 1975; De Camilli et al., 1976), the patients who persistently respond abnormally to TRH are not to be regarded as cured. The disappearance of the abnormal GH response to TRH after surgery probably indicates satisfactory treatment of acromegaly (Faglia et al., 1978). In this study, the basal serum GH level dropped to less than $5 \mathrm{ng} / \mathrm{ml}$ after surgery and abnormal GH response to TRH disappeared (Fig. 2). These findings indicate that a nearly complete resection of the pituitary adenoma was obtained. Serum GH did not
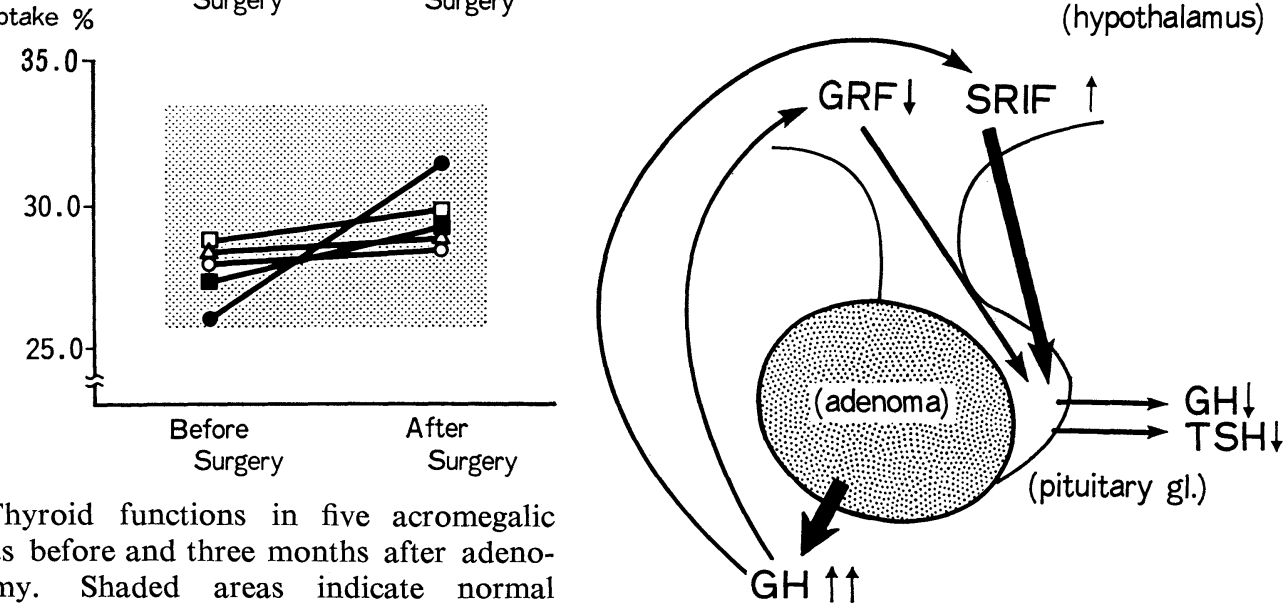
mectomy. Shaded areas indicate normal ranges. - , patient No. 1; $\mathrm{O}-\mathrm{O}$, patient No. 2; $\square$, patient No. 3; $\square-\square$, patient No. 4; $\boldsymbol{\Delta}-\boldsymbol{\Lambda}$, patient No, 6 ,

Fig. 6. The possible mechanism by which GH and TSH secretion from the intact pituitary gland is suppressed in acromegalic patients. 
increase with insulin hypoglycemia even after surgery in these patients (Fig. 1). These results indicate that $\mathrm{GH}$ secretion from the intact part of the pituitary gland is impaired in acromegalic patients.

A decrease in TSH has been observed more frequently in acromegalic patients $(68 \%)$ than in patients with prolactinoma (36\%) (Miyai and Uozumi, 1976). Although the response of TSH to TRH was decreased before adenomectomy in our patients, the TSH response improved after the operation. The secretion of TSH is regulated mainly by the level of circulating thyroid hormones and by TRH. Somatostatin infusion has been found to suppress TSH secretion in normal subjects (Hall et al., 1973; Siler et al., 1974 ; Weeke et al., 1974) and in patients with hypothyroidism (Lucke et al., 1975). Elevation of the basal TSH level following administration of somatostatin antiserum has been observed in rats (Arimura et al., 1976; Ferland et al., 1976). These findings indicate that somatostatin has an inhibitory effect on TSH secretion.

The mechanisms by which TSH secretion decreases in acromegaly are not clarified yet. Possible explanations include (i) an adenoma may decrease the function of thyrotrophs by a pressure upon a normal pituitary gland, (ii) the thyroid gland that is often hypertrophic in acromegalic patients may secrete excessive thyroid hormones and result in the suppression of TSH secretion by negative feedback, and (iii) a raised hypothalamic somatostatin level due to increased GH secretion from the pituitary adenoma of acromegalic patients may inhibit TSH secretion, as well as GH secretion from the intact part of the pituitary gland.

If the first hypothesis is correct, the TRH-stimulated TSH concentration in patients with prolactinoma should be as low as in acromegalic patients. However, the patients with prolactinoma showed a stronger TSH response to TRH than the acromegalic patients, as shown in Fig. 3. The second possibility is unlikely because the serum $T_{3}$ and $\mathrm{T}_{4}$ levels were normal or subnormal in all the patients except patient No. 6 (Fig. 5). The secretion of $\mathrm{GH}$ and TSH from the intact pituitary gland may be inhibited by increased somatostatin secretion from the hypothalamus. The excessive $\mathrm{GH}$ that is secreted from a tumor may suppress GRF secretion and accelerate somatostatin secretion from the hypothalamus (Fig. 6). It is also possible that the improvement in TSH secretion after surgery, when the GH level dropped to below $5 \mathrm{ng} / \mathrm{ml}$, may be due to a release from the inhibitory effect of somatostatin.

There have been many reports which support the last hypothesis. Berelowitz et al. (1981) reported that the somatostatin content in the hypothalamus was distinctly increased and the capability of somatostatin secretion in vitro was increased compared with controls when GH was administered to rats. However, the ability to secrete somatostatin from the hypothalamus decreased when an adenomectomy was performed or $\mathrm{GH}$ antiserum was administered. Furthermore, it has been shown that the somatostatin concentration in pituitary portal blood rises when $\mathrm{GH}$ is administered to the third ventricle of the rat (Chihara et al., 1981). These results indicate that at least some of the negative feedback mechanisms involved in $\mathrm{GH}$ secretion are caused by a variation in hypothalamic somatostatin.

Lippe et al. (1975) reported that in four of six children with idiopathic $\mathrm{GH}$ deficiency who became hypothyroid during treatment with exogenous GH, TRH-stimulated TSH concentrations were either absent or reduced.

In this context it has been postulated by Hall et al. (1978) that GH may induce the synthesis and release of somatostatin via a short-loop positive feedback, and that the increased endogenous level of somatostatin would in turn suppress both GH and TSH release.

Three of the six patients had a serum 
$\mathrm{T}_{3}$ level lower than normal (Fig. 5). We could not find a correlation between the serum $\mathrm{T}_{3}$ level and the response of TSH to TRH. Klijn et al. (1980) compared the functions of the pituitary-thyroidal axis in acromegalic patients and patients with hyperprolactinemia and a pituitary tumor. They found a positive correlation between the TRH-stimulated TSH concentration and $\mathrm{T}_{3}$ level but not between the TRH-stimulated TSH concentration and the $\mathrm{T}_{4}$ level in the patients with prolactinoma, while in the acromegalic patients there was no correlation between TSH reserve and the level of $\mathrm{T}_{3}$ or $T_{4}$. Serum $T_{3}, T_{4}, T_{3}$-uptake levels and free $T_{4}$ indices did not change significantly after adenomectomy as compared with those before the operation in five of the six patients studied, although all of the patients were almost completely cured by the operation (Table 1 and Fig. 5). Therefore, the impaired TSH secretion may scarcely affect thyroid function in acromegalic patients.

The decreased TSH secretion in acromegalic patients may be due to increased secretion of hypothalamic somatostatin caused by an excess of GH. If one can measure the levels of somatostatin and GRF in the hypothalamus and pituitary portal blood in acromegalic patients, it will be helpful in verifying this.

\section{Acknowledgements}

The authors express their appreciation to Professor Kiyoshi Miyai (the Central Laboratory for Clinical Investigation, Osaka University Hospital) for measuring serum $\mathrm{T}_{3}, \mathrm{~T}_{4}, \mathrm{~T}_{3}$-uptake and TSH, and to Miss Yayoi Hayakawa for typing the manuscript.

\section{References}

Arimura, A., A. Gordin and A. Schally (1976). Increase in basal and thyrotropin-releasing hormone-stimulated secretion of thyrotropin and the effects of triiodothyronine in rats passively immunized with antiserum to somatostatin. Fed. Proc. 35, 782,

Berelowitz, M., S. L. Firestone and L. A. Frohman (1981). Effects of growth hormone excess and deficiency on hypothalamic somatostatin content and release and on tissue somatostatin distribution. Endocrinology 109, 714-719.

Chihara, K., N. Minamitani, H. Kaji, A. Arimura and T. Fujita (1981). Intraventricularly injected growth hormone stimulates somatostatin release into rat hypophysial portal blood. Endocrinology 109, 2279-2281.

De Camilli, P., L. Tagliabue, A. Paracchi, P. BeckPeccoz, G. Faglia and M. Giovanelli (1976). In vitro effect of TRH on the release of $\mathrm{GH}$ by fragments of GH-producing human pituitary adenomas. European Workshop on Treatment of Pituitary Adenomas, Rottach-Egern (abstract).

Faglia, G., P. Beck-Peccoz, C. Ferrari, P. Travaglini, B. Ambrosi and A. Spada (1973). Plasma growth hormone response to thyrotropin-releasing hormone in patients with active acromegaly. J. Clin. Endocrinol. Metab. 36, 12591262.

Faglia, G., A. Paracchi, C. Ferrari and P. BeckPeccoz (1978). Evaluation of the results of trans-sphenoidal surgery in acromegaly by assessment of the growth hormone response to thyrotrophin-releasing hormone. Clin. Endocrinol. 8, 373-380.

Ferland, L., F. Labrie, M. Jobin, A. Arimura and A. V. Schally (1976). Physiological role of somatostatin in the control of growth hormone and thyrotropin secretion. Biochem. Biophys. Res. Commun. 68, 149-156.

Giovanelli, M. A., E. D. F. Motti, A. Paracchi, P. Beck-Peccoz, B. Ambrosi and G. Faglia (1976). Treatment of acromegaly by transsphenoidal microsurgery. J. Neurosurg. 44, 677-686.

Giustina, G., E. Reschini, M. Peracchi, L. Cantalamessa, F. Cavagnini, M. Pinto and P. Bulgheroni (1974). Failure of somatostatin to suppress the thyrotropin releasing factor and luteinizing hormone releasing factor-induced growth hormone release in acromegaly. J. Clin. 
Endocrinol. Metab. 38, 906-909.

Gual, C., A. J. Kastin and A. V. Schally (1972). Clinical experience with hypothalamic releasing hormones. Part 1. Thyrotropin-releasing hormone. Recent Prog. Hormone Res. 28, 173-200.

Hall, R., B. J. Ormston, G. M. Besser, R. J. Cryer and M. McKendrick (1972). The thyrotropinreleasing hormone test in diseases of the pituitary and hypothalamus. Lancet 1, 759-763.

Hall, R., G. M. Besser, A. V. Schally, D. H. Coy, D. Evered, D. J. Goldie, A. J. Kastin, A. S. McNeilly, C. H. Mortimer, C. Phenekos, W. M. G. Tunbridge and D. Weightman (1973). Actions of growth hormone-release inhibiting hormone in healthy men and in acromegaly. Lancet 2, 581-584.

Hall, R., M. Snow, M. Scanlon, B. Mora and A. Gomez-Pan (1978). Pituitary effects of somatostatin. Metabolism 27, 1257-1262.

Hoyte, K. M. and J. B. Martin (1975). Recovery from paradoxical growth hormone responses in acromegaly after transsphenoidal adenomectomy. J. Clin Endocrinol. Metab. 41, 656-659.

Irie, M. and T. Tsushima (1972). Increase of serum growth hormone concentration following thyrotropin-releasing hormone injection in patients with acromegaly or gigantism. J. Clin. Endocrinol. Metab. 35, 97-100.

Karlberg, B., S. Almqvist and S. Werner (1971). Effects of synthetic pyroglutamyl-hystidyl-proline-amide on serum levels of thyrotrophin, cortisol, growth hormone, insulin and PBI in normal subjects and patients with pituitary and thyroid disorders. Acta Endocrinol. 67, 288-302.

Klijn, J. G. M., S. W. J. Lamberts, R. Doctor, F. H. De Jong, K. J. Van Dongen and J. C. Birkenhager (1980). The function of the pituitary-thyroidal axis in acromegalic patients $\mathrm{v}$. patients with hyperprolactinemia and a pituitary tumor. Clin. Endocrinol. 13, 577-585.
Kumahara, Y., K. Miyai, T. Hashimoto and T. Onishi (1975). Aging and anterior pituitary function...responses of PRL, TSH and gonadotropins to TRH and LH-RH in normal subjects. Jpn. J. Geriatr. 12, 363-371.

Lippe, B., A. Van Herle, S. Lafranchi, R. P. Uller, N. Lavin and S. A. Kaplan (1975). Reversible hypothyroidism in growth hormone-deficient children treated with human growth hormone. J. Clin. Endocrinol. Metab. 40, 612-618.

Lucke, C., B. Hoffken and A. Von Zur Muhlen (1975). The effect of somatostatin on TSH levels in patients with primary hypothyroidism. J. Clin. Endocrinol. Metab. 41, 1082-1084.

Miyai, K. and T. Uozumi (1976). A. Brain tumor 6. Central nervous diseases and hormonal secretion (in Japanese). In: Brain and hormone (H. Imura and K. Miyai ed.), The 8th Lake Kawaguchi Conference, Ishiyaku, Japan. p.p. 153-171.

Sakoda, M., M. Otsuki, N. Hiroshige, K. Kanao, A. Yagi and M. Honda (1970). Effect of synthetic thyrotropin-releasing factor (TRF) on pituitary TSH secretion in man. Endocrinol. Japon. 17, 541-549.

Samaan, N. A., M. E. Leavens and R. H. Jesse, Jr. (1974). Serum growth hormone and prolactin response to thyrotropin-releasing hormone in patients with acromegaly before and after surgery. J. Clin. Endocrinol. Metab. 38, 957-963.

Siler, T. M., S. S. C. Yen, W. Vale and R. Guillemin (1974). Inhibition by somatostatin on the release of TSH induced in man by thyrotropin-releasing factor. J. Clin. Endocrinol. Metab. 38, 742-745.

Weeke, J., A. Prange-Hansen and K. Lundbaek (1974). The inhibition by somatostatin of the thyrotropin response to thyrotropin-releasing hormone in normal subjects. Scand. J. Clin. Lab. Invest. 33, 101-103. 